\title{
Professional Landscapes at the End of Education
}

FEDERICO GARCIA LAMMERS

South Dakota State University
This project is based on an assumption about the end of architectural education. Most formal architectural education culminates in two paths: the individual thesis project or the practice-based internship. The latter path is wrought with the practicalities of professional anticipation, while the former is bound by disciplinary expectations to articulate novel theories. This project focuses on a graduate studio that addresses how to end architectural education by combining professional practice, precedent study, and speculative research.

The work from the studio is a forensic investigation into the decision-making and execution of an existing building. In their last semester of study, graduate students collaborate with one architecture firm to research the critical workflows of that practice. Through the making of time-based images, students explore professional networks by fetishizing ubiquitous and seemingly dull processes, such as, meeting minutes, field observations, specifications, emails, etc. There is a great deal of "non-architecture" work performed by architects and introduced to students in professional practice courses. Many faculty and professionals remark with frustration, "I worked on emails, RFIs, specs, etc. I didn't do architecture today." What would happen if processes that are typically excluded from graphical representation had to be used to articulate the ideation and execution of a building?

Since 2016, there have been twenty students, six professional practices, fifteen architects, and three faculty involved in the studio. Practitioners facilitate the exchange of existing data, arrange site visits, and participate in studio reviews. To frame the student work, Forensics is referred to in three ways: 1. Referring to the forum and the practice of making an argument before a professional or academic gathering; 2 . Referring to the techniques used to develop investigative strategies and tactics; 3. Referring to the non-linear sequencing of events. These three criteria are synthesized into three steps that connect the studio schedule with its intellectual scope.

The first step is an investigation of the building's effects basic functions and the relationships among owner, architect, financiers, and building professionals. After being connected to the project's architects, engineers, contractors, and clients, students interrogate the situation and graphically dissect the building. The second step is connecting the facts of the project into a plausible story of how the project reached its end. In this phase, students are graphically mapping out webs of interconnectivity between people, tools, and place. Webs are mapped by analyzing documents and data shared by the architecture firms. The third step is the graphical telling of each of these stories of a building process, and representing the building to the project's progenitors. The three steps are based on linking broad disciplinary questions to under examined professional processes.

The results from the studio are a series of data-driven landscapes that articulate the immaterial decisions affecting the practice of architecture in a specific place. In a technical age of expansive communication tools, these professional data landscapes highlight disciplinary questions rooted in architectural authority. This work hinges on the ability to theorize about professional work, instead of professionalizing theoretical work. 


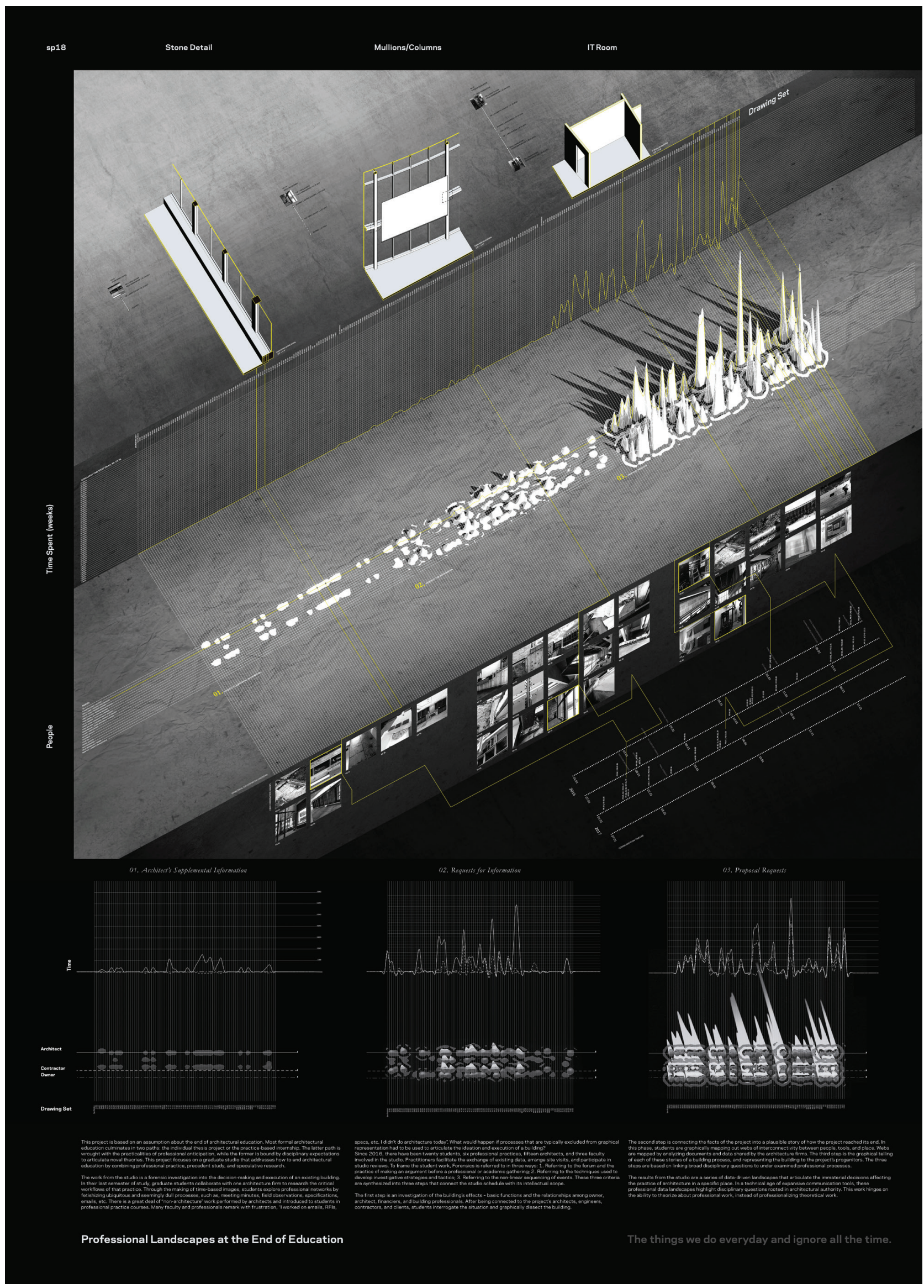

